and has served as the fire commissioner for the city of Los Angeles for the past year. In 2006, he received the AAFP's Nikitas Zervanos National Outstanding Residency Program Director Award and in 2009 received the Physician Humanitarian Award from the Medical Board of California. Dr Hara will serve the ABFM on the Executive Committee, the Bylaws Committee, the Operations Committee, the Examination Committee, the Audit/Finance Committee, the Research \& Development Committee, the MC-FP Committee, and the Credentials Committee as its Chair.

The ABFM welcomes 4 new members to the board of directors:

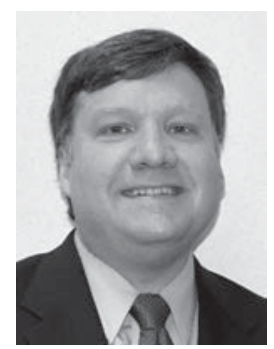

Joseph W. Gravel, Jr, MD is the chief medical officer for the Lawrence Family Health Center and the residency program director for the Lawrence Family Medicine Residency. Prior to this, Dr Gravel served as residency program director of the Tufts University Family Medicine Residency for 14 years and also as medical director of the Sharewood Project, a free clinic in Malden, Massachusetts. He is the immediate past president of the Massachusetts Academy of Family Physicians (MassAFP). Dr Gravel will serve the ABFM on the Operations Committee and the Examination Committee.

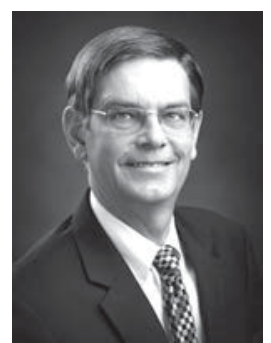

Jerry E. Kruse, MD, MSPH is a professor in both the Department of Family \& Community Medicine and Medical Education, and executive associate dean at Southern Illinois University School of Medicine. Prior to this, Dr Kruse spent 9 years as the executive director of the Quincy Family Medicine Programs, and 19 years on the faculty of the Quincy Family Practice Residency Program, serving as assistant program director for 9 years and as program director for 12 years. Dr Kruse will serve the ABFM on the Research and Development Committee and the Communications/Publications Committee.

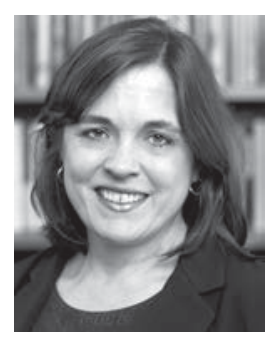

Lorna Anne Lynn, MD is the director of Practice Assessment Development and Evaluation and staff administrator for the Conflict Of Interest Committees for the American Board of Internal Medicine (ABIM). Prior to this, she served as the ABIM's director of PIM research for 4 years and as the director of recertification development for 9 years. Dr Lynn will serve the ABFM on the Examination Committee and the MC-FP Committee.

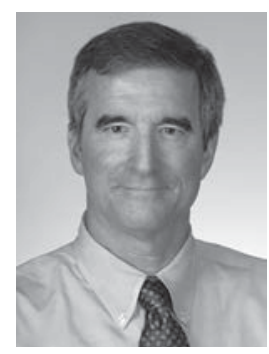

David E. Soper, MD is the vice chairman and director of the Division of Academic Specialists in General Obstetrics and Gynecology in the Department of Obstetrics and Gynecology at the Medical University of South Carolina (MUSC). He is also the J. Marion Sims Professor of Obstetrics and Gynecology at MUSC. Dr Soper will serve the ABFM on the Credentials Committee and the Communications/Publications Committee.

The remaining current members of the board are: Elizabeth G. Baxley, MD of Greenville, North Carolina, Diane Beebe, MD of Jackson, Mississippi, Laura M. Brooks, MD of Lynchburg, Virginia; Montgomery Douglas, MD of Valhalla, New York ${ }_{i}$ Christine C. Matson of Norfolk, Virginia, David E. Mercer, MD of Omaha, Nebraska, Marcia J. Nielsen, PhD of Lawrence, Kansas; Kailie R. Shaw, MD of Tampa, Florida; and Keith L. Stelter, MD of Mankato, Minnesota.

Jane Ireland

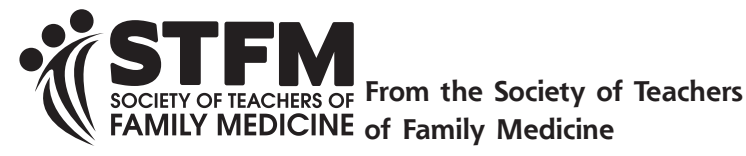

Ann Fam Med 2014;12:480-481. doi: 10.1370/afm.1706.

\section{STFM BEGINS UPDATE OF ITS STRATEGIC PLAN}

The STFM Strategic Planning Committee (SPC) has embarked on an update of the STFM Strategic Plan for 2015-2018.

As part of the update, the SPC is assessing the previous goals and strategies and the achievements of the organization in relation to the current plan. The committee is also reviewing results of extensive data collected over the last 2 years from the STFM member needs survey, various membership focus groups, and regular program assessments.

The Board of Directors and Committees have been extremely dedicated to using, monitoring, and measuring the effectiveness of our current Strategic Plan," says Sam Cullison, MD, STFM president. "The Strategic Planning Committee has a great foundation as we begin this update." 
The updated plan will focus on 5 key strategic priorities, including professional and leadership development, scholarship, workforce recruitment and retention, policy advocacy, and professional relationships. The SPC is taking into account current and future issues faced by family medicine educators as it reviews 71 areas of importance and hones in on a prioritized list of strategies.

The committee will also examine the plan's alignment with Family Medicine for America's Health, including meeting faculty development needs, aligning family medicine entrustable professional activities into training, and improving clerkship sites.

SPC members include: Sam Cullison, MDi Mary Hall, $\mathrm{MD}_{i}$ John Saultz, MDi Beat Steiner, MD, $\mathrm{MPH}_{i}$ Larry Mauksch, MEd; Sarina Schrager, MDi Gretchen Dickson, MDi Steven Zweig, MD; and Stacy Brungardt, CAE.

The SPC will be working on the update through fall 2014 with plans to have a preliminary draft of the 2015-2018 Strategic Plan for review by the STFM Board of Directors in February 2015. STFM uses its strategic plan to guide the organization and its activities. The original plan was developed in 2011 for 2012-2014

Traci Nolte

STFM Director of Publications and Community

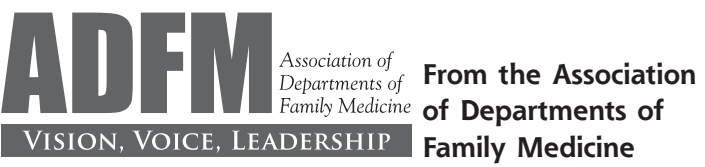

Ann Fam Med 2014;12:481-482. doi: 10.1370/afm.1702.

\section{EVOLVING PERSPECTIVES ON POPULATION HEALTH MANAGEMENT}

Health care costs are unevenly distributed, with a small percent of patients accounting for most health care costs in this country. ${ }^{1,2} \mathrm{~A}$ population health perspective is necessary to understand and address the complex needs of patients in the high risk, high cost segment.

In the late 1980s and 1990s, managed care, characterized by "gatekeeping" and heavy-handed utilization authorization, was a version of population cost management. ${ }^{3}$ Contemporary population health approaches, exemplified by highly integrated delivery systems such as Kaiser Permanente and Geisinger are achieving demonstrable success in the Triple Aims of better care, healthy people/healthy communities, and affordable care. ${ }^{4}$ Current approaches to managing the most complex chronically ill patients range from turning over their care to highly specialized academic medical centers to building a longitudinal relationship with a primary care medical home employing highly functional interprofessional teams. In contrast to the managed care of the 1990s, the current medical home models are without strict gatekeeping and promote a cooperative relationship between primary care and specialists to create a highly coordinated medical neighborhood.

Academic health centers will always deliver quaternary services that few community providers can provide and will maintain a unique patient mix. They cannot succeed, however, in the new health care paradigm of population health without a strong primary care base. Primary care physicians provide the majority of care to patients with chronic illness in the United States. ${ }^{5}$ Nearly one-half (42\%) of patients with chronic illness have more than a single condition ${ }^{6}$ and are, therefore, ill-suited for disease-specific, specialty-based medical homes. Primary care physicians comprehensively attend to the multiple medical needs and social needs of these patients, while collaborating with specialists as appropriate. These patients with multimorbidity are not a static group rather, they frequently move from health to serious medical exacerbation and back to better health. These transitions in health status accompany changes in their life situations, which is why having primary care-based population management and continuity of relationships is critical. Mounting evidence indicates that advanced models of primary care are increasing value, especially for this subgroup of patients in the highest tier of medical costs. ${ }^{7}$

We, in the Association of Departments of Family Medicine (ADFM), recognize that academic health centers are not Kaiser Permanente and Geisinger. Many departments of family medicine around the country are vigorously engaged in the movement to transform care and to create high-performing medical homes and medical neighborhoods at academic health centers. A major pressure most academic health centers are currently facing is a need to enhance primary care capabilities to provide even the institution's own employees with highly accessible, well-coordinated, affordable care. We have devoted considerable effort in ADFM to understand how we can help move our academic health centers from volume-based to valuebased care delivery ${ }^{8}$ with the ultimate goal of delivering the Triple Aim to all populations served by these large institutions.

As we look to the future, we need to partner with others to proactively facilitate work of many individuals and organizations to address delivery of health care to populations within our communities. We applaud 